Bangladesh J. Bot. 44(1): 45-50, 2015 (March)

\title{
ASSESSMENT OF GENETIC AND EPIGENETIC VARIATIONS IN POTATO SOMATIC HYBRIDS BY METHYLATION-SENSITIVE ISSR AND RAPD MARKERS
}

\author{
Jagesh Kumar Tiwari*, Shaumaya Saurabh, Poonam Chandel, \\ Bir Pal Singh and Vinay BhardwaJ
}

Central Potato Research Institute, Shimla, Himachal Pradesh 171 001, India

Key words: DNA methylation, In vitro propagation, Potato, Somatic hybrids

\begin{abstract}
Genetic and epigenetic changes (DNA methylation) in the mother plants of somatic hybrids (1st cycle) and their regenerants (30th cycles sub-cultured) were analyzed using methylation-sensitive ISSR and RAPD markers. ISSR and RAPD profiles and their cluster analyses based on the Jaccard's similarity coefficient revealed $100 \%$ genetic similarity among the mother plant and their regenerants. While for the epigenetic changes in the samples, the MS-ISSR markers detected DNA methylation $(2.7 \%)$ in the regenerants compared to the mother plant (1\%), whereas MS-RAPD markers detected a little methylation patterns in the regeneratns $(0.6 \%)$ compared to the mother plants $(0.4 \%)$.
\end{abstract}

\section{Introduction}

In potato, in vitro clonal propagation is used to produce micro- or mini-tubers for healthy seed stocks identical to mother plant after repeated sub-culturing. However, in vitro cultures pose a problem of genetic stability caused by genetic and epigenetic variations (somaclonal variations) in regenerants (Zilberman and Henikoff 2007). It is well known from the past that epigenetics controls gene expression without altering DNA sequence and leads to quite stable genetic modifications which are frequently transmitted to daughter cells (Smulders and de Klerk 2011). Until now, the best known epigenetic process is DNA methylation, partly because it has been the easiest to study with existing technology and plays a key role in regulating gene expression. Detection of DNA methylation may depends on the application of restriction enzymes such as isoschizomers. Isoschizomers share the same recognition sites but show differential sensitivity to DNA methylation. Polymorphic DNA fragments can be generated after digestion of methylated genomic DNA with isoschizomers (Chen 2007). These isoschizomers recognise the same tetranucleotide sequence $\left(5^{\prime}-3^{\prime}\right)$ CCGG but have different sensitivities to the cytosines methylation. The enzyme HpaII will cut the external cytosines is hemi-methylated (only a single DNA strand is methylated), whereas $M s p I$ will cleave the internal cytosines is fully-methylated. On the other hand, for a given DNA sample, two major methylation sites, namely i) full methylation of internal cytosine and ii) hemi-methylation of external cytosine can only be distinguished using isochimeres HpaII and MspI. They cannot distinguish between unmethylated and fully methylated cytosines or hemi-methylated internal cytosines (McClelland et al. 1994).

Among various molecular markers, a simple detection method of methylated DNA was developed by an addition of methylation-sensitive restriction digestion of genomic DNA prior to RAPD analysis, the simplest method for detection of DNA polymorphisms (Powell et al. 1996; Zarghami et al. 2008; Nakamura and Hosaka 2010). In addition, ISSR markers have been proven to be quite efficient in detecting genetic fidelity in several crop species for example Solanum species (Aversano et al. 2009), Lilium orientalis (Liu and Yang 2012) and Malus domestica

*Author for correspondence: <jageshtiwari@gmail.com>. 
(Pathak and Dhawan 2012). The aim of this study was to detect genetic and epigenetic variations in in vitro propagated somatic hybrids mother plants and their regenerants using conventional and methylation-sensitive ISSR and RAPD markers.

\section{Materials and Methods}

In the present study, previously developed in vitro propagated interspecific potato somatic hybrids of dihaploid Solanum tuberosum 'C-13' (+) S. pinnatisectum (CGN No.: 17745) were used (Sarkar et al. 2011). Twelve 'mother plants' of somatic hybrids (P1, P2, P3, P4, P5, P6, P7, P8, P9, P10, P12 and P13) and their corresponding 12 (one each) 'regenerants' (P1r, P2r, P3r, P4r, P5r, P6r, P7r, P8r, P9r, P10r, P12r and P13r) were examined in the study. 'Mother plants' $\left(1^{\text {st }}\right.$ cycle: original mother plant regenerated from one callus in the previous study of Sarkar et al. 2011) and $30^{\text {th }}$ cycles sub-cultured 'regenerants' of the respective somatic hybrids were analyzed for genetic and epigenetic changes. Plant DNA was isolated from $100 \mathrm{mg}$ leaves collected from fresh in vitro plants using the GenElute Plant Genomic DNA MiniPrep Kit (Sigma-Aldrich, St. Louis, USA).

To detect genetic changes among the mother plant and the regeneratns, ISSR analysis was performed using genomic DNA with 16 primers described by Aversano et al. (2009) and Bidani et al. (2007). MS-ISSR analysis was carried out to detect epigenetic changes using restricted genomic DNA by the restriction enzymes HpaII and MspI (New England Biolabs, Ipswitch, USA) separately at $37^{\circ} \mathrm{C}$ for overnight as per the manufacturer's instruction followed by PCR amplification and gel documentation as above in the ISSR analysis.

To detect genetic changes among the mother plant and the regenerants, RAPD analysis was performed using genomic DNA with seven primers described previously by Sarkar et al. (2011). MS-RAPD analysis was carried out like MS-ISSR.

A datum matrix was constructed on the basis of presence (1) or absence (0) of bands of the amplified DNA fragments. Genetic diversity analysis was performed with the program NTSYSPC 2.21 (Rohlf 2006). A similarity matrix was calculated by Jaccard's coefficient and the dendrogram was generated using unweighted pair-group method (UPGMA) clustering method.

\section{Results and Discussion}

To detect genetic changes 16 ISSR primers yielded 118 scorable bands among the mother plants and their regenerants, of which 10 (8.4\%) were polymorphic bands (Table 1$)$. The average number of bands generated by each primer pair was 7.3, with an average of 0.6 polymorphic bands. In addition, seven RAPD primers yielded 56 scorable bands among the mother plants and their regenerants, of which 4 (7.1\%) were polymorphic bands (Table 1$)$. The average number of bands generated by each primer pair was 8.0 , with an average of 0.57 polymorphic bands. In the study, ISSR and RAPD profiles resulted into complete genetic similarity and no variations were observed among the mother plants and their corresponding regenerants. Moreover, none of the loss of original bands of the mother plants or gain of novel bands in the regenerants were observed by the both analyses. In ISSR and RAPD analyses, cluster analyses based on the Jaccard's similarity coefficients revealed $100 \%$ genetic similarity among the mother plants and their regenerants (Fig. 1). In the study, the somatic hybrid mother plant and regenerants had been independently sub-cultured by nodal cuttings in tissue culture for the last three years. There are a number of findings which report on detection of genetic fidelity using molecular markers in crops such as Solanum species (Aversano et al. 2009) and Lilium orientalis (Liu and Yang 2012). Aversano et al. (2009) demonstrated that under in vitro culture conditions Solanum genotype affects the integrity of the genome and absence of polymorphism at plastid level confirms the 
greater genetic stability of cytoplasmic DNA. Kumar et al. (2011) assessed genetic fidelity with similarity level of $100 \%$ of micropropagated plants and mother plants of jojoba using RAPD and ISSR markers. Liu and Yang (2012) analysed micropropagated progenies and mother plant of lily could be grouped with 92\% similarity level. However, Dann and Wilson (2011) detected genetic differences ranged from 8.75 to $15.63 \%$ by amplified fragment length polymorphism (AFLP) in long-term nodal tissue culture potato clones compared to our study where no genetic differences in the somatic hybrids mother plants and their regenerants.

Table 1. Alteration in cytosine DNA methylation level in the mother plants of somatic hybrids and their regenerants based on 16 MS-ISSR markers.

\begin{tabular}{|c|c|c|c|c|c|}
\hline \multirow[b]{2}{*}{ Sample } & \multirow[b]{2}{*}{$\begin{array}{l}\text { Total } \\
\text { bands }\end{array}$} & \multirow{2}{*}{$\begin{array}{l}\text { Unmethylated } \\
\text { CCGG sites } \\
(\%)\end{array}$} & \multicolumn{3}{|c|}{ Methylated CCGG sites } \\
\hline & & & $\begin{array}{l}\text { Fully methylated sites } \\
\text { (internal cytosines) (\%) }\end{array}$ & $\begin{array}{l}\text { Hemi-methylated sites } \\
\text { (external cytosines) (\%) }\end{array}$ & $\begin{array}{l}\text { Total } \\
\text { methylation (\%) }\end{array}$ \\
\hline \multicolumn{6}{|c|}{ Mother plants of somatic hybrids (1st cycle of original plants) } \\
\hline $\mathrm{P} 1$ & 135 & $133(98.5)$ & $2(1.4)$ & 0 & $2(1.4)$ \\
\hline $\mathrm{P} 2$ & 137 & $137(100)$ & 0 & 0 & 0 \\
\hline P3 & 130 & $127(97.6)$ & $2(1.5)$ & $1(0.7)$ & $3(2.2)$ \\
\hline P4 & 135 & $133(99.2)$ & $1(0.7)$ & $1(0.7)$ & $2(1.4)$ \\
\hline P5 & 141 & $140(99.2)$ & $1(0.7)$ & 0 & $1(0.7)$ \\
\hline P6 & 140 & $140(100)$ & 0 & 0 & 0 \\
\hline P7 & 140 & 139 (99.2) & 0 & $1(0.7)$ & $1(0.7)$ \\
\hline P8 & 132 & $132(100)$ & 0 & 0 & 0 \\
\hline P9 & 136 & $132(97.0)$ & $2(1.4)$ & $2(1.4)$ & $4(2.8)$ \\
\hline $\mathrm{P} 10$ & 138 & 137 (99.2) & $1(0.7)$ & 0 & $1(0.7)$ \\
\hline $\mathrm{P} 12$ & 141 & $141(100)$ & 0 & 0 & 0 \\
\hline $\mathrm{P} 13$ & 136 & $132(97.0)$ & $3(2.2)$ & $1(0.7)$ & $4(2.9)$ \\
\hline Total & 1641 & $1623(99.0)$ & $12(0.7)$ & $6(0.3)$ & $18(1.0)$ \\
\hline \multicolumn{6}{|c|}{ Regenerants of somatic hybrids (30th cycles sub-cultured plants) } \\
\hline P1r & 141 & $135(95.7)$ & $3(2.1)$ & $3(2.1)$ & $6(4.2)$ \\
\hline $\mathrm{P} 2 \mathrm{r}$ & 140 & 137 (97.9) & $2(1.4)$ & $1(0.7)$ & $3(2.1)$ \\
\hline $\mathrm{P} 3 \mathrm{r}$ & 138 & $132(95.7)$ & $4(2.9)$ & $2(1.4)$ & $6(4.3)$ \\
\hline $\mathrm{P} 4 \mathrm{r}$ & 142 & $136(95.8)$ & $4(2.8)$ & $2(1.4)$ & $6(4.2)$ \\
\hline $\mathrm{P} 5 \mathrm{r}$ & 143 & $141(98.6)$ & $1(0.7)$ & $1(0.7)$ & $2(1.4)$ \\
\hline P6r & 143 & 141 (98.6) & 0 & $2(1.4)$ & $2(1.4)$ \\
\hline P7r & 143 & 140 (97.9) & $2(1.4)$ & $1(0.7)$ & $3(2.1)$ \\
\hline P8r & 139 & 133 (95.7) & $4(2.9)$ & $2(1.4)$ & $6(4.3)$ \\
\hline P9r & 143 & 138 (96.5) & $1(0.7)$ & $4(2.8)$ & $5(3.5)$ \\
\hline P10r & 140 & 139 (99.3) & $1(0.7)$ & 0 & $1(0.7)$ \\
\hline $\mathrm{P} 12 \mathrm{r}$ & 143 & 142 (99.3) & $1(0.7)$ & 0 & $1(0.7)$ \\
\hline $\mathrm{P} 13 \mathrm{r}$ & 143 & 138 (96.5) & $4(2.8)$ & $1(0.7)$ & $5(3.5)$ \\
\hline Total & 1698 & 1652 (97.3) & 27 (1.6) & $19(1.1)$ & $46(2.7)$ \\
\hline
\end{tabular}

To detect epigenetic changes in the present study, 16 MS-ISSR primers yielded in total 130 to 141 and 138 to 143 clear and reproducible bands in the mother plants of somatic hybrids and their regenerants, respectively (Table 1). The numbers of total, non-methylated, hemi-methylated and fully-methylated CCGG sites were calculated based on the MS-ISSR profiles. In the mother plants, out of total 1641 bands, 1623 (99.0\%) unmethylated, 12 (0.7\%) fully methylated and 6 $(0.3 \%)$ hemi-methylated sites were amplified. Total methylation level in the mother plants was 
$1.0 \%$ (varied between 0.0 and $2.9 \%$ ), which was comprised of methylation at the internal cytosines (0.0 and $1.5 \%)$ and external cytosines (0.0 and $1.4 \%)$. Whereas, in the regenerants, out of total 1698 MS-ISSR bands, 1652 (97.3\%) unmethylated, 27 (1.6\%) fully methylated and 19 (1.1\%) hemi-methylated sites were amplified. Compared to the mother plant, regenerants showed both kinds of detectable cytosine methylation levels, i.e., full methylation of the internal cytosines and hemi-methylation of the external cytosines, at the CCGG sites. Total methylation level was $2.7 \%$ (varied between 0.7 and $4.3 \%$ ), which was comprised of both full methylation of the internal cytosines $(1.6 \%)$ and hemi-methylation of the external cytosines $(1.1 \%)$ showed higher values compared to the mother plants. Among the regenerants, the highest total methylation sites were 6 (P1r, P3r, P4r and P8r) and the lowest was 1 (P10r and P12r).

Table 2. Alteration in cytosine DNA methylation level in the mother plants of somatic hybrids and their regenerants based on seven MS-RAPD markers.

\begin{tabular}{|c|c|c|c|c|c|}
\hline \multirow[b]{2}{*}{ Sample } & \multirow[b]{2}{*}{$\begin{array}{l}\text { Total } \\
\text { band }\end{array}$} & \multirow[b]{2}{*}{$\begin{array}{l}\text { Unmethylated } \\
\text { CCGG sites (\%) }\end{array}$} & \multicolumn{3}{|c|}{ Methylated CCGG sites } \\
\hline & & & $\begin{array}{l}\text { Fully methylated sites } \\
\text { (internal cytosines) (\%) }\end{array}$ & $\begin{array}{l}\text { Hemi-methylated sites } \\
\text { (external cytosines) (\%) }\end{array}$ & $\begin{array}{l}\text { Total methyla. } \\
\text { (\%) }\end{array}$ \\
\hline \multicolumn{6}{|c|}{ Mother plants of somatic hybrids (1st cycle of original plants) } \\
\hline $\mathrm{P} 1$ & 55 & $55(100)$ & 0 & 0 & 0 \\
\hline $\mathrm{P} 2$ & 57 & $57(100)$ & 0 & 0 & 0 \\
\hline P3 & 57 & $57(100)$ & 0 & 0 & 0 \\
\hline P4 & 52 & $51(98.0)$ & $1(2)$ & 0 & $1(2.0)$ \\
\hline P5 & 55 & $55(100)$ & 0 & 0 & 0 \\
\hline P6 & 55 & $55(100)$ & 0 & 0 & 0 \\
\hline P7 & 57 & $57(100)$ & 0 & 0 & 0 \\
\hline P8 & 50 & 49 (98.0) & 0 & $1(2.0)$ & $1(2.0)$ \\
\hline P9 & 53 & $53(100)$ & 0 & 0 & 0 \\
\hline $\mathrm{P} 10$ & 56 & 55 (98.2) & $1(1.8)$ & 0 & $1(1.8)$ \\
\hline $\mathrm{P} 12$ & 57 & $57(100)$ & 0 & 0 & 0 \\
\hline $\mathrm{P} 13$ & 51 & $51(100)$ & 0 & 0 & 0 \\
\hline Total & 655 & $652(99.6)$ & $2(0.3)$ & $1(0.1)$ & $3(0.4)$ \\
\hline \multicolumn{6}{|c|}{ Regenerants of somatic hybrids (30th cycles sub-cultured plants) } \\
\hline $\mathrm{P} 1 \mathrm{r}$ & 55 & $55(100)$ & 0 & 0 & 0 \\
\hline $\mathrm{P} 2 \mathrm{r}$ & 57 & $57(100)$ & 0 & 0 & 0 \\
\hline $\mathrm{P} 3 \mathrm{r}$ & 57 & $57(100)$ & 0 & 0 & 0 \\
\hline $\mathrm{P} 4 \mathrm{r}$ & 53 & $52(98.1)$ & $1(1.9)$ & 0 & $1(1.8)$ \\
\hline $\mathrm{P} 5 \mathrm{r}$ & 57 & $57(100)$ & 0 & 0 & 0 \\
\hline P6r & 57 & 57 (100) & 0 & 0 & 0 \\
\hline $\mathrm{P} 7 \mathrm{r}$ & 57 & 57 (100) & 0 & 0 & 0 \\
\hline P8r & 52 & 50 (96.1) & $1(1.9)$ & 1 (1.9) & $2(3.8)$ \\
\hline $\mathrm{P} 9 \mathrm{r}$ & 53 & $53(100)$ & 0 & 0 & 0 \\
\hline P10r & 57 & 56 (98.2) & 0 & $1(1.7)$ & $1(1 . \%)$ \\
\hline $\mathrm{P} 12 \mathrm{r}$ & 57 & 57 (100) & 0 & 0 & 0 \\
\hline $\mathrm{P} 13 \mathrm{r}$ & 51 & $51(100)$ & 0 & 0 & 0 \\
\hline Total & 663 & 659 (99.4) & $2(0.3)$ & $2(0.3)$ & $4(0.6)$ \\
\hline
\end{tabular}

Seven MS-RAPD primers yielded in total 50 - 57 and 51 - 57 clear and reproducible bands in the mother plants of somatic hybrids and their regenerants, respectively (Table 2). The numbers of total, non-methylated, hemi-methylated and fully-methylated CCGG sites were calculated based on the MS-RAPD profiles. In the mother plants, out of total 655 bands, 652 (99.6\%) 
unmethylated, $2(0.3 \%)$ fully methylated and $1(0.1 \%)$ hemi-methylated sites were amplified. Total methylation level in the mother plants was $0.4 \%$, which was comprised of similar methylation levels at the internal and external cytosines ( 0.0 and $2.0 \%)$. Total methylation level was $0.6 \%$ (varied between 0.0 and $3.8 \%$ ), which was comprised of the internal and external cytosines $(0.3 \%$ each). Among the regenerants, the highest total methylation sites observed in P4r, P8r and P10r.

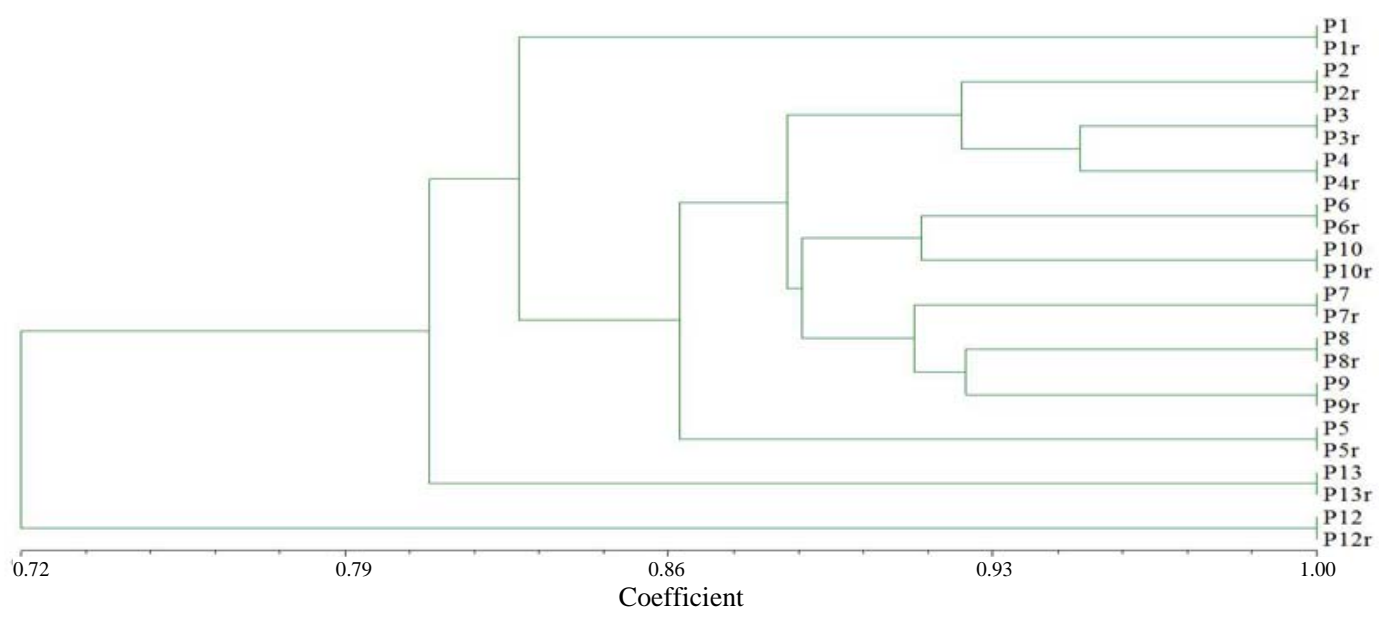

Fig. 1. Cluster analyses based on Jaccard similarity coefficient of ISSR and RAPD combined profiles showing complete genetic similarity among the mother plants (P1, P2, P3, P4, P5, P6, P7, P8, P9, P10, $\mathrm{P} 12$ and P13) of somatic hybrids and their corresponding regenerats IP1r, P2r, P3r, P4r, P5r, P6r, P7r, P8r, P9r, P10r, P12r and P13r)

The MS-ISSR markers revealed higher cytosines methylation in the regenerants (2.7\%) compared to their corresponding mother plants (1.0\%). Whereas, MS-RAPD markers resulted into a few cytosines methylation in the regenerants $(0.6 \%)$ compared to their corresponding mother plants $(0.4 \%)$. RAPD analysis is the simplest method for detection of DNA polymorphisms (Powell et al. 1996). The scored RAPD bands were clarified as methylation-sensitive DNA fragments as digested by the restriction enzymes, which could be unmethylated or hemi- or fullmethylated. Nakamura and Hosaka (2010) investigated for the status of DNA methylation by a simple method using genomic DNA digested by methylation-sensitive restriction enzymes prior to RAPD analysis. However, Dann and Wilson (2011) observed higher epigenetic (12.56 - 26.13\%) variations among regenerants of potato derived from long-term nodal tissue culture by methylation-sensitive amplified polymorphism (MSAP).

Our study indicated long-term nodal tissue culture induced epigenetic variations in the potato somatic hybrids regenerants. Moreover, DNA methylation is generally recognized to suppress gene expression as regulatory factors, homozygosity/heterozygosity of methylated DNA may be involved in inbreeding depression/heterosis (Nakamura and Hosaka 2010). This study provides further insight into the molecular mechanisms involved epigenetic variations in the somatic hybrids regeneration. Further experiments are needed to elucidate the causal relationships at DNA sequence levels in the somatic hybrids. Extensive sequencing of the methylation-sensitive fragments and their gene expression analyses may be a valuable strategy to examine genomic regions most affected by genetic and epigenetic changes. 


\section{Acknowledgements}

The authors are grateful to the Indian Council of Agricultural Research, New Delhi, India for providing financial supports and necessary facilities to carry out research work.

\section{References}

Aversano R, Savarese S, Nova JMD, Frusciante L, Punzo M and Carputo D 2009. Genetic stability at nuclear and plastid DNA level in regenerated plants of Solanum species and hybrids. Euphytica 165: 353-361.

Bidani A, Nouri-Ellouz O, Lakhoua L, Sihachakr D, Cheniclet C, Mahjoub A, Drira N and Gargouri-Bouzid R 2007. Interspecific potato somatic hybrids between Solanum berthaultii and Solanum tuberosum L. showed recombinant plastome and improved tolerance to salinity. Plant Cell Tiss. Org. Cult. 91: 179189.

Dann AL and Wilson CR 2011. Comparative assessment of genetic and epigenetic variation among regenerants of potato (Solanum tuberosum) derived from long-term nodal tissue-culture and cell selection. Plant Cell Rep. 30: 631-639.

Kumar S, Mangal M, Dhawan AK and Singh N 2011. Assessment of genetic fidelity of micropropagated plants of Simmondsia chinensis (Link) Schneider using RAPD and ISSR markers. Acta Physiol. Plant. 33: 2541-2545.

Liu X and Yang G 2012. Adventitious shoot regeneration of oriental lily (Lilium orientalis) and genetic stability evaluation based on ISSR marker variation. In Vitro Cell. Devel. Biol.-Plant 48: 172-179.

McClelland M, Nelson M and Raschke E 1994. Effect of site-specific modification on restriction endonucleases and DNA modification methyltransferases. Nucleic Acid. Res. 22: 3640-3659.

Nakamura S and Hosaka K 2010. DNA methylation in diploid inbred lines of potatoes and its possible role in the regulation of heterosis. TAG 120: 205-214.

Pathak H and Dhawan V 2012. ISSR assay for ascertaining genetic fidelity of micropropagated plants of apple rootstock Merton 793. In Vitro Cell. Develop. Biol.-Plant 48: 137-143.

Powell W, Morgante M, Andre C, Hanafey M, Vogel J, Tingey S, Rafalski A 1996. The comparison of RFLP, RAPD, AFLP and SSR (microsatellite) markers for germplasm analysis. Mol. Breed. 2: 225-238.

Rohlf F 2006. NTSYSpc: Numerical taxonomy system (ver. 2.2). Exeter Publishing, Ltd., Setauket, NY, USA.

Sarkar D, Tiwari JK, Sharma Su, Poonam, Sharma Sa, Gopal J, Singh BP, Luthra SK, Pandey SK and Pattanayak D 2011. Production and characterization of somatic hybrids between Solanum tuberosum L. and S. pinnatisectum Dun. Plant Cell Tiss. Org. Cult. 107: 427-440.

Smulders MJM and de Klerk GJ 2011. Epigenetics in plant tissue culture. Plant Growth Regul. 63: 137-146

Zarghami R, Pirseyedi M, Hasrak S, Sardrood BP 2008. Evaluation of genetic stability in cryopreserved Solanum tuberosum. Afr. J. Biotech. 7: 2798-2802.

Zilberman D and Henikoff S 2007. Genome-wide analysis of DNA methylation patterns Development 134: 3959-3965. 